\title{
Editorial for Special Issue: "Global Vegetation and Land Surface Dynamics in a Changing Climate"
}

\author{
Pinki Mondal ${ }^{1,2, *(1)}$ and Sonali Shukla McDermid ${ }^{3}$ \\ 1 Department of Geography and Spatial Sciences, University of Delaware, Newark, DE 19716, USA \\ 2 Department of Plant and Soil Sciences, University of Delaware, Newark, DE 19716, USA \\ 3 Department of Environmental Studies, New York University, New York, NY 10003, USA; sps246@nyu.edu \\ * Correspondence: mondalp@udel.edu
}

Citation: Mondal, P.; McDermid, S.S. Editorial for Special Issue: “Global Vegetation and Land Surface Dynamics in a Changing Climate". Land 2021, 10, 45. https://doi.org/ 10.3390/land10010045

Received: 29 December 2020

Accepted: 4 January 2021

Published: 6 January 2021

Publisher's Note: MDPI stays neutral with regard to jurisdictional clai$\mathrm{ms}$ in published maps and institutional affiliations.

Copyright: (C) 2021 by the authors. Licensee MDPI, Basel, Switzerland. This article is an open access article distributed under the terms and conditions of the Creative Commons Attribution (CC BY) license (https:// creativecommons.org/licenses/by/ $4.0 /)$.
Global ecosystem changes have multiple drivers, including both natural variability and anthropogenic climate and environmental change. Intensifying climate change, inclusive of increased hydroclimate variability and extremes, temperatures, $\mathrm{CO}_{2}$ fertilization effects, and even changes in cloud cover can produce competing vegetation responses, changes in underlying soil and land surface health, and drive overall changes in ecosystem productivity [1-3]. Anthropogenic pressures also extend beyond climate change to include the clearing of native forests and other vegetation for fuel, fiber, food, increasing infrastructure and municipal development, as well as the intensive management and expansion of agricultural lands and soils for crop production, which can result in vegetation and ecosystem degradation and/or wholesale losses.

Furthermore, these individual climate and environmental drivers incite complex vegetation and ecosystem interactions and feedbacks that can exacerbate each other and/or produce competing effects that make identifying robust ecosystem changes challenging [4]. As one example, atmospheric $\mathrm{CO}_{2}$ fertilization effects are known to decrease plant water demand via reductions in stomatal conductance [5,6]. However, enhanced atmospheric $\mathrm{CO}_{2}$ can also increase leaf area index (LAI), thereby increasing total evapotranspiration (ET) and offsetting the stomatal effects $[7,8]$. While this can cool the surface, particularly in arid to semi-arid regions [9], enhanced ET may also exacerbate soil moisture declines driven by extended dry seasons, reduced snowpack and more variable rainfall. Such feedbacks may imperil greening trends, particularly in more water-limited regions, under future climate and land use trajectories. To resolve these interactions, we must move beyond observations of "greening" and "browning" (a decline in ecosystem productivity) alone towards more integrated climate and vegetation information. It is thus important that ecosystem monitoring and evaluation incorporate measures of the relative presence and influence of these feedbacks, in addition to tracking changes in vegetation and greening/browning.

Of the numerous climate and environmental drivers, a substantial fraction of global greening has been attributed to $\mathrm{CO}_{2}$ fertilization effects, with regional climate changes also driven partly by nutrient deposition, and land management and change [2,10,11]. Nevertheless, there still remain outstanding uncertainties in the drivers of greening vs. browning at regional and local scales. These uncertainties stem from limitations in both the observational products, such as to identify specific vegetation types and transitions, and in ecosystem models' ability to represent complex vegetation processes and competing biophysical responses, such as mortality and disturbances, changes in land use change and management, time-varying vegetation changes under different forcing trajectories $[7,12,13]$ and other biotic factors like pests and diseases. Future climate changes and intensifying land management will bring additional, interactive changes to natural and managed ecosystems. Managing these ecosystems for current and future changes requires an improved understanding of these multiscale drivers of vegetation dynamics, the mechanisms by which they operate, and how they change over time. This special issue in Land draws 
together a collection of five articles covering geographic regions in Africa, Asia and North America [14-18]. Taken together, these articles encompass a wide range of study spanning the biophysical drivers (e.g., hydrological) of vegetation change and dynamics and the human impacts (e.g., perceptions of climate change effects) in both natural and managed ecosystems.

Ugbaje and Bishop [14] examine the relative importance of hydrological controls such as soil moisture, precipitation and terrestrial water storage in determining vegetation greenness in Africa. Using a multivariate analysis, the authors report that precipitation and soil moisture are the most important predictors of vegetation greenness. However, anomalies in vegetation greenness were best predicted by the anomalies in soil moisture and terrestrial water storage in most of Africa with a diminished role of precipitation. The authors also note that predominantly positive trends in vegetation greenness anomalies might be a result of factors other than water availability, such as atmospheric fertilization, use of high yielding crop varieties, afforestation and an increase in growing season length [14].

Globally, an encroachment of woody species into savanna biomes potentially threatens important ecosystem attributes and functionality for both natural processes and human use. However, much uncertainty remains in identifying key drivers of woody encroachment and their interactions with key species, as well as in developing analytical techniques conducive to scaling these dynamics across species and the larger ecosystem. Meyer et al. [15] focus on the Kalahari landscape in Botswana as a test case to understand the environmental drivers determining woody species composition and structure. Their work moves beyond single-species analyses to consider morphological groups, which enable their findings to potentially be scaled across the greater ecosystem. They employ statistical analysis techniques that are more suitable to the distributions that characterize ecological data, making them more informative to land managers. Based on species identified, diversity and abundance data collected at multiple transects, the authors find that precipitation largely explains species richness and abundance when all morphological groups were considered together. However, precipitation was often mediated by other key factors, such that low grazing and fire also contributed to higher species richness. In contrast to previous studies, they also find that higher grazing, as indicated by increased borehole density and cattle numbers, can lead to reduced woody species abundance due to more frequent rotation of cattle and thus less soil disturbance [15].

Comer et al. [16] utilize an integrated exposure-sensitivity-adaptive capacity framework to examine climate change vulnerability of 52 major vegetation types in the western United States. The proposed framework aims to highlight the interactions between climateinduced stress and other ecological stressors. Such interactions might force natural plant communities to transform in unprecedented ways, due to their already reduced resilience. With a reproducible and transparent Habitat Climate Change Vulnerability Index (HCCVI), the authors provide an early warning system of elevated risks for natural plant species, especially valuable for the conservation practitioners. The authors find that currently 50 out of 52 vegetation types have at least moderate vulnerability, while no vegetation type exhibits very high vulnerability. Yet, when mid-21st century climate exposure projections are considered, all but 19 vegetation types shift to the high vulnerability category. They conclude that by measuring relative severity, this framework would be of particular use for gauging risk of environmental degradation for the next several decades [16].

Ongoing changes in weather parameters, such as precipitation and temperature, are known to impact crop yield in different ways. It is also well-documented that adaptation strategies in response to such changes can limit negative impacts on crop yield. Rondhi et al. [17] examine the role of climate change impact perception on farmer adaptation practices by analyzing household survey data from 87,330 farmers in Indonesia. The authors use an ordered probit regression model to analyze the effects of 17 variables from a range of factors: economic, technical, institutional and climatic. All climatic variables have a statistically significant positive impact on the farmers' perceived impact, with floods being identified as the most damaging climatic event, followed by drought, heavy rain 
and other hazards such as landslides. While there is little evidence to indicate any difference between actual impact and perceived impact, it is important to characterize farmers' perceived impact and factors affecting it. An exaggerated perceived impact might lead to maladaptive outcomes, such as excessive application of chemical fertilizer, which has implications for water and soil quality, and ultimately crop health [17].

Improving characterizations of ecosystem responses to drought in East Africa is both urgent, due to intensifying anthropogenic climate change and land use pressures, and challenging, owing to limitations in ground-based measurement and observations. The emergence and proliferation of satellite-based products can offer a variety of ways to monitor ecosystem change in the highly-variable East African climate, but there is a need to better understand how these products capture important ecosystem stress signals. To address this need, Robinson et al. [18] analyze how the normalized difference vegetation index (NDVI) and the solar-induced chlorophyll fluorescence (SIF) capture one of the more exceptional, recent drought periods in East Africa: the failure of both the 2010 "short" and 2011 "long" rainy seasons. They further provide a mechanistic characterization of the drought's temporal evolution, contextualizing it within regional anthropogenic climate trends. They find that despite constraints on its spatial resolution and lower energy, SIF does indeed capture vegetation drought stress similar to NDVI, both instantaneously and at a lag, which gives confidence in its use as an early indicator of regional drought conditions. Nevertheless, they stress that instruments designed with the intention of capturing drought-induced ecosystem stress are critical to the improvement and enhanced utility of SIF measurements. Robinson et al.'s analysis also highlights how reduced rainfall in one season, in this case the 2010 short rains, can compound the effects of regional drought during the subsequent long rains, exacerbating water-stress impacts to both natural and human ecosystems. This is an important temporal dynamic to better understand and monitor, as the Indian Ocean continues to warm and interact with other oceanic and atmospheric variability and change, thereby changing East African regional atmospheric circulation patterns and moisture convergence [18].

The studies included in this special issue represent a diversity of global regions, scales of analysis and analytical techniques, and highlight perspectives on both human and natural land system change. Nevertheless, some common and key messages can be distilled from these works. Firstly, while some ecosystem drivers, e.g., hydroclimate variability, emerge as being of primary importance, they are also mediated by several other factors such as fire [15], and even gender [17]. Such interactions underscore the complexity and dynamism of both natural and human ecosystem responses to global environmental change, which must increasingly be accounted for in quantitative analysis techniques. In addition, several of these studies highlight that key drivers of ecosystem change may themselves be subject to time-varying trends that potentially influence their magnitude, timing, and/or interactions with other drivers or different ecosystem components. Furthermore, all of these studies highlight the importance of improved research, by way of data collection and analysis techniques, instrumentation (e.g., satellite sensor) development, and indicators and metrics for future evaluations of global and regional ecosystem change. These advances are critical to help inform and guide not only novel research, but also more effective decisionmaking for landscape and ecosystem managers in an era of increasing anthropogenic pressures.

Author Contributions: Conceptualization, P.M. and S.S.M.; writing—original draft preparation, P.M. and S.S.M.; writing-review and editing, P.M. and S.S.M. All authors have read and agreed to the published version of the manuscript.

Funding: This research received no external funding.

Acknowledgments: We thank all the reviewers for their feedback on earlier versions of the manuscripts in this Special Issue.

Conflicts of Interest: The authors declare no conflict of interest. 


\section{References}

1. Notaro, M.; Vavrus, S.; Liu, Z. Global vegetation and climate change due to future increases in $\mathrm{CO}_{2}$ as projected by a fully coupled model with dynamic vegetation. J. Clim. 2007, 20, 70-90. [CrossRef]

2. Zhu, Z.; Piao, S.; Myneni, R.B.; Huang, M.; Zeng, Z.; Canadell, J.G.; Ciais, P.; Sitch, S.; Friedlingstein, P.; Arneth, A.; et al. Greening of the Earth and its drivers. Nat. Clim. Chang. 2016, 6, 791-795. [CrossRef]

3. D'odorico, P.; Bhattachan, A.; Davis, K.F.; Ravi, S.; Runyan, C.W. Global desertification: Drivers and feedbacks. Adv. Water Resour. 2013, 51, 326-344. [CrossRef]

4. Bajželj, B.; Richards, K. The Positive Feedback Loop between the Impacts of Climate Change and Agricultural Expansion and Relocation. Land 2014, 3, 898-916. [CrossRef]

5. Donohue, R.J.; Roderick, M.L.; McVicar, T.R.; Farquhar, G.D. Impact of $\mathrm{CO}_{2}$ fertilization on maximum foliage cover across the globe's warm, arid environments. Geophys. Res. Lett. 2013, 40, 3031-3035. [CrossRef]

6. Higgins, S.I.; Scheiter, S. Atmospheric $\mathrm{CO}_{2}$ forces abrupt vegetation shifts locally, but not globally. Nature 2012, 488, $209-212$. [CrossRef] [PubMed]

7. Mankin, J.S.; Smerdon, J.E.; Cook, B.I.; Williams, A.P.; Seager, R. The Curious Case of Projected Twenty-First-Century Drying but Greening in the American West. J. Clim. 2017, 30, 8689-8710. [CrossRef] [PubMed]

8. Zhang, K.; Kimball, J.S.; Nemani, R.R.; Running, S.W.; Hong, Y.; Gourley, J.J.; Yu, Z. Vegetation Greening and Climate Change Promote Multidecadal Rises of Global Land Evapotranspiration. Sci. Rep. 2015, 5, 15956. [CrossRef] [PubMed]

9. Forzieri, G.; Alkama, R.; Miralles, D.G.; Cescatti, A. Satellites reveal contrasting responses of regional climate to the widespread greening of Earth. Science 2017, 356, 1180-1184. [CrossRef] [PubMed]

10. Mao, J.; Ribes, A.; Yan, B.; Shi, X.; Thornton, P.E.; Séférian, R.; Ciais, P.; Myneni, R.B.; Douville, H.; Piao, S.; et al. Human-induced greening of the northern extratropical land surface. Nat. Clim. Chang. 2016, 6, 959-963. [CrossRef]

11. Chen, C.; Park, T.; Wang, X.; Piao, S.; Xu, B.; Chaturvedi, R.K.; Fuchs, R.; Brovkin, V.; Ciais, P.; Fensholt, R.; et al. China and India lead in greening of the world through land-use management. Nat. Sustain. 2019, 2, 122-129. [CrossRef] [PubMed]

12. Levis, S. Modeling vegetation and land use in models of the Earth System. Wiley Interdiscip. Rev. Clim. Chang. 2010, 1, 840-856. [CrossRef]

13. Mahowald, N.; Lo, F.; Zheng, Y.; Harrison, L.; Funk, C.; Lombardozzi, D.; Goodale, C. Projections of leaf area index in earth system models. Earth Syst. Dyn. 2016, 7, 211-229. [CrossRef]

14. Ugbaje, S.U.; Bishop, T.F.A. Hydrological control of vegetation greenness dynamics in Africa: A multivariate analysis using satellite observed soil moisture, terrestrialwater storage and precipitation. Land 2020, 9, 15. [CrossRef]

15. Meyer, T.; Holloway, P.; Christiansen, T.B.; Miller, J.A.; D'Odorico, P.; Okin, G.S. An assessment of multiple drivers determining woody species composition and structure: A case study from the Kalahari, Botswana. Land 2019, 8, 122. [CrossRef]

16. Comer, P.J.; Hak, J.C.; Reid, M.S.; Auer, S.L.; Schulz, K.A.; Hamilton, H.H.; Smyth, R.L.; Kling, M.M. Habitat climate change vulnerability index applied to major vegetation types of thewestern interior United States. Land 2019, 8, 108. [CrossRef]

17. Rondhi, M.; Khasan, A.F.; Mori, Y.; Kondo, T. Assessing the role of the perceived impact of climate change on national adaptation policy: The case of rice farming in Indonesia. Land 2019, 8, 81. [CrossRef]

18. Robinson, E.S.; Yang, X.; Lee, J.-E. Ecosystem Productivity and Water Stress in Tropical East Africa: A Case Study of the 2010-2011 Drought. Land 2019, 8, 52. [CrossRef] 